\title{
Rentabilidad en la banca universal venezolana: período 2008-2010
}

\author{
Nava Rosillón, Marbelis Alejandra*
}

\begin{abstract}
Resumen
En el sector bancario, la rentabilidad incluye la evaluación de las ganancias con respecto a las operaciones efectuadas para determinar la incidencia de los factores del entorno en la utilidad obtenida. El objetivo de esta investigación es analizar la tendencia de los indicadores de rentabilidad de la banca universal en Venezuela durante el período 2008-2010, en promedio por estratos agrupados según las captaciones del público. Es un estudio descriptivo con diseño documental y dimensión longitudinal de tendencia. Los resultados muestran rendimiento promedio de la cartera de crédito similar entre los estratos de la banca privada; la banca pública y el estrato pequeño de la banca privada mostraron la mayor rentabilidad en sus inversiones en títulos valores. También, la banca pública alcanzó mayor rentabilidad con respecto al costo bruto de sus pasivos pero más bajo margen financiero por la intermediación. El estrato grande obtuvo el mayor rendimiento de sus inversiones en activos y patrimonio. La banca privada muestra mayor rentabilidad y eficiencia que la banca pública. Se infieren niveles de rentabilidad satisfactorios sin diferencias significativas entre los estratos, cuya tendencia es creciente al inicio del período estudiado y decreciente al final.
\end{abstract}

Palabras clave: Rentabilidad, banca universal venezolana, indicadores financieros, sistema bancario venezolano, institución financiera.

\section{Recibido: 10-04-12. Aceptado: 16-04-13}

* Economista. Magíster en Gerencia de Empresas, mención: Gerencia Financiera. Universidad del Zulia (LUZ). Docente en Pregrado y Postgrado en la Universidad Alonso de Ojeda. Acreditada en el Programa de Estímulo a la Investigación e Innovación (PEI). Estado Zulia, Venezuela, e-mail: marbejans@hotmail.com 


\title{
Profitability in the Venezuelan Universal Bank: Period 2008-2010
}

\begin{abstract}
In the banking sector, profitability includes assessing earnings with regard to transactions made in order to determine the effect of environmental factors on the profit. The objective of this research is to analyze the trend of profitability indicators for the Venezuelan universal bank during the $2008-2010$ periods, based on the average per strata classified according to the reception of public capital. It is a descriptive study with a documentary design and a longitudinal trend dimension. The results showed an average yield for the credit portfolio that was similar among the private banking strata. The public bank and the small stratum of the private bank showed the greatest profitability in their security investments. Also, the public bank achieved greater profitability with respect to gross liability costs, but a much lower financial margin through intermediation. The large stratum obtained the greatest profitability from its investments in assets and patrimony. The private universal bank showed greater profitability and efficiency than the public bank. Satisfactory profitability levels were inferred without significant differences among the strata whose trend is increasing at the beginning of the studied period and decreasing at the end.
\end{abstract}

Keyworks: Profitability, Venezuelan universal bank, financial indicators, Venezuelan banking system, financial institution.

\section{Introducción}

El acelerado proceso de cambio predominante en el contexto económico actual ha traído como consecuencia que los países latinoamericanos experimenten reestructuraciones en sus marcos de regulación, bajo la premisa de una mayor profundización y modernización del sistema financiero, lo cual plantea importantes retos a las instituciones financieras y ha facilitado el proceso de fusiones entre ellas.

Venezuela ha sido participe de este fenómeno. Es conocido que desde la década de los años 90 el sistema financiero ha pasado por una serie de transformaciones dada la necesidad de una mayor apertura, modernización y adecuación a los esquemas internacionales de la globalización financiera.

Atendiendo a tales circunstancias, se suscitó una redefinición de normas, polí- ticas y estrategias estableciendo un nuevo marco regulatorio caracterizado por la apertura extranjera, mejoramiento de las funciones de los entes bancarios y la introducción de nuevas formas de intermediación financiera, destacando la Banca Universal (BU) con la visión de incrementar significativamente los niveles de eficiencia y reducir los costos; simultáneamente a ello, esta modalidad de banca dio paso a un proceso de fusiones de las instituciones especializadas que ha resultado favorecedor para el sistema financiero.

Desde entonces, la tendencia es hacia el incremento de los bancos universales y la disminución de las entidades especializadas; pues, hoy en día "la nueva visión del sector bancario contempla dos grandes subsistemas: bancos universales e instituciones microfinancieras. Estos ajustes se irán dando de acuerdo a 
la ley a través de fusiones y transformaciones" (Banco Central de Venezuela (BCV), 2010:220).

Ahora bien, como consecuencia del contexto de los años 90, las instituciones bancarias venezolanas sufrieron una significativa disminución de sus niveles de rentabilidad; razón que acentúa la necesidad de analizar las condiciones operativas de estas entidades en particular de la BU; que actualmente ocupa, junto con la banca comercial, la mayor participación en el total de activos y de las captaciones del público en el sistema bancario.

Ello indica que para toda organización o institución es crucial tener conocimiento sobre sus niveles de rentabilidad para determinar los rendimientos de su actividad en relación con las ventas y la inversión; puesto que, conjuntamente estas relaciones permiten conocer la eficacia operativa de las empresas.

No obstante, al hablar de rentabilidad de un banco se hace referencia a los beneficios que una entidad bancaria genera para sus accionistas; pues se fundamenta en obtener una ganancia mediante una adecuada inversión en activos rentables. Al respecto, Rodríguez et al. (2010) expresan que la rentabilidad se asocia con el amplio diferencial entre las tasas activas y tasas pasivas con las que operan los bancos; por ello, se considera imprescindible que las tasas de interés activas deben ser mayores que las tasas pasivas.

En términos generales, los indicadores de rentabilidad miden la eficiencia del desempeño gerencial llevado a cabo en el negocio bancario; por lo tanto reflejan la capacidad de la banca de obtener ganancias derivadas de sus operaciones.
En razón de lo antes mencionado es fundamental para la BU venezolana operar con el objetivo de disminuir los costos, incrementar los niveles de eficiencia y competitividad, alcanzar economías de escala y aumentar su rentabilidad en pro de un mejor funcionamiento del sistema financiero.

Tomando como fundamento estas premisas, se plantea este trabajo con el objetivo de analizar la tendencia de los indicadores de rentabilidad de la BU en Venezuela durante el período 2008-2010. Para ello, se describen las características de esta modalidad de banca, las posiciones teóricas referentes a la rentabilidad y sus indicadores financieros según la Superintendencia de Instituciones del Sector Bancario (SUDEBAN) y posteriormente se presentan y describen las tablas y gráficos que muestran los valores porcentuales y la evolución de los indicadores trimestrales promedios para cada estrato y para el total de la BU en cada año estudiado.

La presente investigación se considera de tipo descriptivo con diseño documental (Hurtado, 2007) y una dimensión longitudinal de tendencia (Hernández et al., 2003); ya que busca analizar la evolución de los indicadores de rentabilidad de la $\mathrm{BU}$ venezolana durante un período de tiempo específico que abarca desde el año 2008 hasta el año 2010; tomando como base de datos la información publicada en los Boletines Trimestrales emitidos por la SUDEBAN, cuya denominación para el período de estudio era Superintendencia de Bancos.

El universo estudiado se encuentra conformado por el número total de bancos con modalidad universal existentes en el país para el final de cada año de estudio, 
agrupados por estratos según el criterio establecido por la SUDEBAN en función del monto total de las captaciones del público expresados en bolívares fuertes.

Al respecto, es importante destacar que, según SUDEBAN (2008), para finales del año 2008, el monto de las captaciones del público para la banca pública (Bs. 24.764.986) se mantuvo por debajo del monto total de las captaciones de la banca privada (Bs. 185.416.253), pero próximo al monto de las captaciones del estrato pequeño (Bs. 16.412.773); no obstante a finales del año 2009, la banca pública alcanzó un monto por captaciones de Bs. 65.156.308 mayor que el año anterior pero menor que el monto de la banca privada (Bs. 188.738.627) y muy cercano al monto alcanzado por el estrato mediano (Bs. 73.420.967), (SUDEBAN, 2009). En tanto, para el final del año 2010 , la BU experimentó mayores captaciones del público, así lo reflejan las cifras registradas por la Superintendencia; pues, la banca pública alcanzó un monto de Bs. 98.445.143, el cual se mantuvo por debajo de las captaciones de la banca privada (Bs. 222.604.437) pero por encima de las captaciones del estrato mediano (Bs. 79.008.729), (SUDEBAN, 2010).

Ahora bien, para recolectar la información necesaria para este estudio, se procedió, inicialmente a utilizar fuentes secundarias (Méndez, 2001) contenidas en textos, revistas científicas especializadas y los boletines trimestrales emitidos por la SUDEBAN; de estos últimos documentos se tomaron los datos referidos a los indicadores de rentabilidad mensuales para cada entidad bancaria con modalidad universal y se transcribieron en una matriz de datos construida para cada indicador.
Posteriormente, se calcularon los indicadores promedios por cada estrato y para cada trimestre de los años de estudio; para ello, se tomaron los indicadores mensuales por banco publicados en los boletines trimestrales de la SUDEBAN y se calcularon los promedios trimestrales para cada banco; luego, se procedió a calcular los promedios trimestrales por estrato utilizando para ello el programa Excel 2010; esto, con el propósito de determinar si los estratos muestran resultados que revelen diferencias y similitudes entre sí; subsiguiente a ello, se calculó el promedio trimestral de cada indicador para el total de la BU, para enfatizar en los acontecimientos que incidieron en la rentabilidad y sus efectos en el desempeño de estas entidades bancarias en el país durante el tiempo de estudio.

\section{Características de la banca universal en Venezuela}

En Venezuela, la BU se introdujo formalmente con la reforma a la Ley General de Bancos y otras Instituciones Financieras realizada en 1993, la cual reguló la apertura de la inversión extranjera en búsqueda de la modernización y adecuación del sistema financiero a las nuevas tendencias globalizadoras a nivel mundial.

Desde allí, se inició el auge de la BU en el país con la visión de incrementar los niveles de eficiencia, reducir costos y adaptarse a las nuevas condiciones de competitividad. En Venezuela, esta modalidad de banca representa el avance experimentado por el sistema bancario en el transcurso de los años; pues, siempre han existido bancos especializados que realizan actividades específicas, 
pero actualmente el público dispone con mayor facilidad, encontrar todos los servicios y productos financieros en una sola entidad bancaria (Nava, 2011); ya que la BU constituye una institución financiera caracterizada por una gestión integral que ofrece una variedad de servicios múltiples y más eficientes con mayor actualización de sus sistemas, procedimientos, recursos y políticas (Belloso et al., 2005).

Por su parte, la nueva Ley de Instituciones Financieras del Sector Bancario (LISB) (2010) en el Artículo 11 expresa que "se entiende por Banco Universal a las instituciones que realizan todas las operaciones de intermediación financiera y sus servicios conexos, sin más limitaciones que las expresamente establecidas en la presente Ley." Del mismo modo, para Díaz (2004:94) "el Banco Universal es aquella institución bancaria que ofrece la mayoría o todos los servicios financieros que existen en el mercado".

Desde estas perspectivas, se precisa que la BU constituye un ente financiero con competencia para llevar a cabo todas las operaciones que realizan los bancos especializados, cuyas operaciones incluyen todas las actividades implícitas en el proceso de intermediación financiera efectuadas por los bancos comerciales, hipotecarios, banca de inversión, banca de desarrollo, arrendadoras financieras, entidades de ahorro y préstamo, fondos del mercado monetario; caracterizada por una nueva cultura organizacional, mayor capacidad para generar nuevos servicios financieros, integrar funcionalmente los procesos y sistemas, poseer información más completa acerca de sus clientes y disponer de una estructura más adecuada para enfrentar la competencia globalizada.
Muci et al. (2004) consideran que la $\mathrm{BU}$ se caracteriza por la concentración organizativa de una diversidad de actividades y servicios financieros en una misma entidad física y por las múltiples ventajas que se le atribuyen, entre ellas resaltan la reducción cuantitativa de los costos derivados de su implementación resultante de la concentración física del negocio y por la posibilidad de atracción de clientes dada la oferta de una mayor gama de servicios financieros.

Otro aspecto de singular importancia de estas instituciones en el entorno venezolano, se enfoca en que la BU requiere para operar un capital social mínimo tanto suscrito como pagado de Ciento Setenta Millones de Bolívares (Bs. 170.000.000), si tienen su asiento principal en el Área Metropolitana de Caracas, así como en las ciudades de Guarenas, Guatire, San Antonio de los Altos, Carrizal, Los Teques, Los Valles del Tuy y en el Estado Vargas; y de Ochenta y Cinco Millones (Bs. 85.000.000) si se encuentran ubicadas en cualquier otra región del país, previamente calificadas como Bancos Regionales por la SUDEBAN y puede operar a nivel nacional e internacional previa autorización de SUDEBAN y bajo el cumplimiento de otras disposiciones establecidas en el marco legal correspondiente (Asamblea Nacional, 2010).

Aunado a lo anterior, es importante destacar la participación de los bancos universales en el sistema bancario venezolano por cada estrato para el final de cada año estudiado, cuyas cifras se muestran en la Tabla 1, donde se observa que las instituciones bancarias con capital privado tienen la mayor participación dentro del número total de bancos univer- 
Tabla 1

Participación de Bancos Universales con Capital Privado en el Sistema Bancario Venezolano Octubre - Diciembre

\begin{tabular}{ccccccc}
\hline \multirow{2}{*}{$\begin{array}{c}\text { Estratos I } \\
\text { Año }\end{array}$} & \multicolumn{2}{c}{$\mathbf{2 0 0 8}$} & \multicolumn{2}{c}{$\mathbf{2 0 0 9}$} & \multicolumn{2}{c}{$\mathbf{2 0 1 0}$} \\
\cline { 2 - 7 } $\mathbf{N}^{\circ}$ & $\mathbf{\%}$ & $\mathbf{N}^{\circ}$ & $\mathbf{\%}$ & $\mathbf{N}^{\circ}$ & $\%$ \\
\hline Capital Privado & & & & & & \\
Estrato Grande & 4 & 16,7 & 3 & 13,6 & 3 & 14,3 \\
Estrato Mediano & 12 & 50,0 & 9 & 40,9 & 8 & 38,1 \\
Estrato Pequeño & 5 & 20,8 & 6 & 27,3 & 6 & 28,5 \\
Total Capital Privado & $\mathbf{2 1}$ & $\mathbf{8 7 , 5}$ & $\mathbf{1 8}$ & $\mathbf{8 1 , 8}$ & $\mathbf{1 7}$ & $\mathbf{8 0 , 9}$ \\
Capital Público & 3 & 12,5 & 4 & 18,2 & 4 & 19,1 \\
Total & $\mathbf{2 4}$ & $\mathbf{1 0 0}$ & $\mathbf{2 2}$ & $\mathbf{1 0 0}$ & $\mathbf{2 1}$ & $\mathbf{1 0 0}$ \\
\hline
\end{tabular}

Fuente: SUDEBAN (2008-2010).

sales, ya que representan el $87,5 \%$ para el año 2008 , el $81,8 \%$ para el 2009 y $80,9 \%$ para el año 2010 , distribuidas en estrato grande, mediano y pequeño, cuyas cifras reflejan una disminución en el número de bancos universales en el mercado bancario al transcurrir el período de estudio.

Por su parte, los bancos universales con capital público tienen la menor participación dentro de esta modalidad, alcanzando sólo el $12,5 \%$ para el año 2008 , el $18,2 \%$ para el año 2009 y el $19,1 \%$ para el año 2010 , mostrando una tendencia creciente a través de los años estudiados, debido a procesos de fusiones, adquisiciones y creación de nuevas instituciones que permitieron la expansión de la banca pública.

\section{Rentabilidad y sus indicadores en el negocio bancario}

Muchos autores han desarrollado enfoques teóricos para medir la rentabilidad. Gitman (2003) plantea que la renta- bilidad relaciona los rendimientos de la empresa con sus ventas, activos y capital contable. Esto indica que es una medida del rendimiento de una inversión.

Según el Fondo Monetario Internacional (FMI) (2006: 95) "La rentabilidad es un factor determinante en la solidez de las empresas que incide en el crecimiento del capital, la capacidad para superar los acontecimientos adversos y a larga la capacidad de reembolso. Mientras que Brigham et al. (2006: 86) consideran que "la rentabilidad es el resultado de varias políticas y decisiones."

Bajo estas premisas, la rentabilidad expresa la incidencia de la liquidez, de la gestión de los activos y la deuda sobre los resultados de una actividad empresarial. En efecto, la rentabilidad está expresada por la relación entre la ganancia económica obtenida en una actividad económica y los recursos utilizados para llevarla a cabo.

De esta manera, la rentabilidad constituye un indicador que muestra los resultados de las funciones gerenciales y decisiones financieras implementadas en una organización y se expresa como un 
valor porcentual reflejando la eficiencia en las operaciones e inversiones empresariales mediante la utilidad o beneficio que aporta un activo (Nava, 2009).

Haciendo uso de las concepciones anteriores, se infiere que la rentabilidad representa la capacidad de la empresa para generar un nivel satisfactorio de beneficio o lucro, convirtiéndose en el rendimiento del capital invertido y en la compensación del inversionista por el riesgo asumido al realizarla.

Así, la rentabilidad constituye un indicador financiero y a juicio de Block et al. (2001) los indicadores financieros se utilizan para ponderar y evaluar el desempeño operativo de la empresa. Además, estos autores consideran que los indicadores de rentabilidad miden la capacidad de la empresa para ganar un reintegro adecuado sobre las ventas, total de activos y capital invertido; ya que los inconvenientes relacionados con la rentabilidad se pueden explicar por la capacidad de la organización para emplear de manera efectiva sus recursos.

Al respecto, para Van Horne et al. (2002) existen dos tipos de indicadores de rentabilidad, aquellos que expresan la rentabilidad relacionada con las ventas y aquellos que reflejan la rentabilidad con respecto a la inversión, los cuales conjuntamente permiten determinar la eficiencia operativa de la organización.

Específicamente, la rentabilidad como indicador del rendimiento de las instituciones bancarias incluye la evaluación de las ganancias con respecto a las operaciones realizadas, con el fin de determinar la incidencia de los factores internos y externos reinantes en el entorno en la obtención de la utilidad; puesto que las ganancias son primordiales para la cancelación de los dividendos, cubrir las pérdidas crediticias y mantener niveles de reservas suficientes para enfrentar las políticas de crecimiento de la entidad bancaria.

Para efectos de esta investigación se estudiaron los indicadores de rentabilidad establecidos por la SUDEBAN para analizar la rentabilidad de la banca en Venezuela, los cuales se definen a continuación:

- Ingresos por cartera de crédito I cartera de crédito promedio, este indicador mide el grado de rendimiento promedio generado por la cartera de créditos durante un ejercicio determinado. La cuantía de este indicador está estrechamente vinculada con el carácter rentable de la cartera. Un aspecto importante para destacar es que los ingresos por cartera de crédito están referidos a las ganancias financieras devengadas y/o cobradas en el ejercicio por concepto de intereses, comisiones y otros rendimientos arrojados por los activos incluidos en la cartera de créditos; por ello, mientras más alto sea este coeficiente mayor será la rentabilidad de las entidades bancarias.

- Ingresos por inversiones en títulos valores / inversiones en títulos valores promedio, es un indicador que expresa el rendimiento obtenido por la entidad bancaria en sus inversiones en títulos valores, tales como acciones y obligaciones emitidas por empresas públicas y privadas, respecto al volumen de recursos aplicados en la adquisición de estos; es decir, mide la relación existente entre los ingresos generados por las inversiones en títulos valores y la cartera promedio que el banco mantiene en valores. Mientras mayor resulte mayor será la rentabilidad de la institución financiera. 


\section{- Gastos financieros / captacio-} nes promedio con costos, constituye un indicador que mide el costo bruto de los pasivos a cargo del banco; si el costo resulta alto en comparación con otros intermediarios financieros podría deberse a deficiencias en las captaciones de recursos o al pago de altas tasas de interés para compensar una condición de mayor riesgo. Sus variaciones son consecuencia de la composición de los depósitos; por lo tanto, mientras menor sea su valor mayor será la rentabilidad de la banca.

\section{- Margen financiero bruto/activo} promedio, es un indicador que cuantifica el margen financiero (Ingresos Financieros menos Egresos Financieros), que obtiene la entidad bancaria por la intermediación financiera efectuada durante el ejercicio con respecto al saldo en que se calculó el activo del instituto. Está relacionado con la eficiencia gerencial; por ello, mientras mayor sea la eficiencia en la gestión de las tasas pasivas y activas mayor será el coeficiente resultante. En este sentido, se considera que si este indicador alcanza valores mayores al 15\% la gestión de las tasas de interés es bastante satisfactoria pero si se ubica por debajo del $9 \%$ indica ineficiencia en el manejo del diferencial de las mismas (Linares, 2001).

\section{- Ingresos extraordinarios/acti-} vo promedio, expresa la relación existente entre los recursos obtenidos por la institución bancaria, en virtud de la ejecución de transacciones de carácter no recurrente o eventual con el promedio del activo del instituto. Representa mayor transparencia dado el importante aporte de los ingresos no propios del negocio bancario a la utilidad liquida. Es de gran relevancia destacar que este indicador no se determinó en este estudio debido a la insuficiencia en la información aportada por la base de datos consultada.

- Resultado neto/activo promedio (ROA), es la rentabilidad proveniente de las operaciones del negocio bancario. Mide la capacidad del balance del banco para generar resultados operacionales. Es un indicador enfocado en medir la efectividad y eficiencia con la que se utilizan los activos necesarios para llevar a cabo la actividad bancaria, lo cual se traduce en la proporción de las ganancias que obtiene el banco por su inversión en activos. Mientras más alto sea este coeficiente significa mayor rendimiento por las colocaciones de la cartera (préstamos e inversiones).

- Resultado neto / patrimonio promedio (ROE), mide el nivel de rendimiento del patrimonio del instituto una vez efectuadas las transferencias necesarias para apartados. Este indicador expresa las ganancias, en términos porcentuales, generadas en función del capital aportado por los accionistas o propietarios del negocio bancario; en otras palabras, mide la rentabilidad de los recursos propios. Se estima que si este coeficiente se ubica por encima de $60 \%$ revela alto rendimiento de los recursos propios pero al ubicarse por debajo del $30 \%$ es indicativo de niveles de rentabilidad muy bajos (Linares, 2001).

\section{Indicadores de rentabilidad en la banca universal venezolana}

En esta sección se presentan y analizan los resultados de los indicadores de rentabilidad promedios para cada estrato estudiado y para el total de la BU ve- 
nezolana, mostrando los valores relativos de estos indicadores y una comparación gráfica de su evolución trimestral durante el período de estudio.

\subsection{Ingresos por cartera de crédito/ cartera de crédito promedio}

La Tabla 2 muestra el rendimiento promedio generado por la cartera de crédito para cada uno de los estratos de la banca privada y para la banca pública; en la cual se puede observar que el estrato grande mantuvo cifras muy similares desde inicios del año 2008 hasta el segundo trimestre del año 2009 que oscilan entre $21,14 \%$ y $23,10 \%$; a partir de allí comienza una tendencia descendente hasta finales de 2010 cuando cae a 20,01\%.

Para el estrato mediano, se aprecia una tendencia creciente durante el año 2008 hasta el primer trimestre del 2009 , lo cual refleja una cartera de crédito rentable en el mediano plazo, posteriormente inicia una disminución poco variable que se mantiene hasta el último año estudiado alcanzando $19,97 \%$.

Con respecto al estrato pequeño, este indicador refleja un comportamiento fluctuante en el año 2008, alcanzando cifras que oscilan entre $20,72 \%$ y $23,53 \%$, recuperándose en el primer trimestre del $2009(26,53 \%)$ y partir del segundo trimestre de ese año comenzó un descenso significativo que alcanzó $18,93 \%$ para el final del año 2010. Mientras tanto, la banca pública muestra resultados promedios muy bajos en relación con los estratos de la banca privada; pues, para el primer trimestre de 2008 se ubicó en $12,45 \%$ creciendo a $14,42 \%$ para el segundo trimestre, pero para los trimestres siguientes se situó en $13,94 \%$ y $13,30 \%$ respectivamente; a partir del año 2009 se observa

Tabla 2

Ingresos por cartera de crédito/cartera de crédito promedio*

\begin{tabular}{ccccccc}
\hline Años & $\begin{array}{c}\text { Trimestres/ } \\
\text { Estratos }\end{array}$ & Grande & Mediano & Pequeño & $\begin{array}{c}\text { Banca } \\
\text { Pública }\end{array}$ & $\begin{array}{c}\text { Banca } \\
\text { Universal }\end{array}$ \\
\hline 2 & Mar & 21,14 & 21,33 & 21,65 & 12,45 & 19,14 \\
0 & Jun & 21,78 & 22,54 & 23,53 & 14,42 & 20,57 \\
0 & Sep & 23,10 & 23,87 & 20,72 & 13,94 & 20,41 \\
8 & Dic & 22,76 & 23,67 & 23,29 & 13,30 & 20,75 \\
2 & Mar & 22,97 & 23,35 & 26,49 & 14,00 & 21,70 \\
0 & Jun & 22,56 & 22,88 & 25,53 & 14,04 & 21,25 \\
0 & Sep & 21,97 & 22,41 & 24,50 & 16,32 & 22,63 \\
9 & Dic & 21,61 & 21,88 & 22,91 & 14,07 & 21,96 \\
2 & Mar & 20,09 & 20,09 & 19,52 & 15,62 & 18,83 \\
0 & Jun & 20,14 & 20,02 & 19,61 & 15,58 & 18,84 \\
1 & Sep & 20,38 & 20,14 & 19,57 & 15,28 & 18,84 \\
0 & Dic & 20,01 & 19,97 & 18,93 & 15,29 & 18,56 \\
\hline
\end{tabular}

${ }^{*}$ Cifras relativas promedio por estrato y para el total de la Banca Universal

Fuente: Estimaciones Propias con base en la Información publicada por SUDEBAN (2008-2010). 
una tendencia creciente que se mantuvo hasta el final del período estudiado, lo que indica una cartera de crédito rentable para las entidades públicas (Tabla 2).

Por su parte, el Gráfico 1 permite comparar la evolución del indicador ingresos por cartera de crédito/cartera de crédito promedio entre los estratos. De allí, se deduce que los tres estratos de la banca privada presentaron una tendencia similar durante los años estudiados independientemente de su tamaño en función de las captaciones del público. La banca pública mostró una tendencia creciente con cifras inferiores a las alcanzadas por los estratos de la banca privada; reflejando menor rentabilidad en relación a sus ingresos por cartera de crédito. En términos generales, estas cifras expresan una mayor rentabilidad de la BU con capital privado con respecto a la $\mathrm{BU}$ de capital público.

Aunado a ello, es importante resaltar que los resultados arrojados por este indicador sugieren niveles de rendimiento satisfactorios de la cartera de crédito; pues para el año 2008 evidenció incrementos en todos los estratos, aún cuando la tendencia de la actividad crediticia fue decreciente detectando que los préstamos al sector comercial y familiar ejercieron mayor peso en el total de la cartera (BCV, 2008). Para el año 2009, la cartera de crédito de la BU experimentó leves incrementos entre los trimestres. En el tercer trimestre, el estrato grande mostró disminución, los estratos mediano y pequeño revelaron leves aumentos mientras que la banca del Estado presentó un incremento significativo; no obstante, para el final del año los aumentos de la cartera fueron poco transcendentales en todos los estratos, excepto el estrato pequeño que evidenció una mínima disminución, cifras registradas pese al descenso de la actividad económica de los sectores productivos que se sustentan con financiamiento (BCV, 2009).

Asimismo, la cartera de crédito de la BU para el año 2010 mostró variaciones poco significativas para el primer semestre pero a partir del segundo semes-

\section{Gráfico 1 \\ Ingresos por cartera de crédito/cartera de crédito promedio entre los estratos estudiados}

$\%$

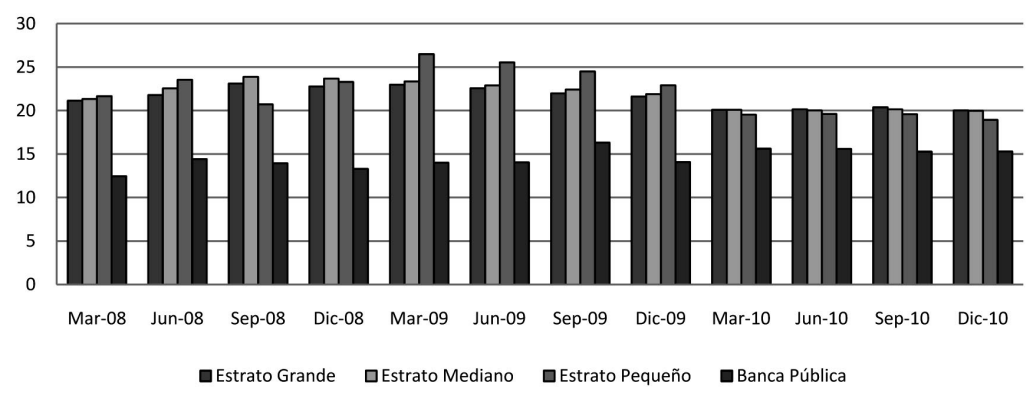

Fuente: Estimaciones propias con base en la información publicada por SUDEBAN (2008-2010). 
tre comenzaron ciertos incrementos excepto el estrato pequeño cuya cartera se mantuvo constante. Estos resultados están vinculados al bajo dinamismo que presentó la actividad crediticia en el país durante los primeros meses del año, cuyo desempeño mejoró para los dos últimos trimestres (BCV, 2010). Es de hacer notar que mientras más altos sean los ingresos por cartera de crédito más alta será la rentabilidad de la entidad bancaria.

El Gráfico 2 muestra la evolución promedio de este indicador para el total de la $\mathrm{BU}$, el cual refleja una tendencia muy similar durante los años 2008 y 2009 ubicándose entre $19,14 \%$ y $22,63 \%$ con fluctuaciones poco significativas, disminuyendo en el 2010 entre 18,56\% y $18,84 \%$. Se considera que en estos resultados incidió la tendencia decreciente que sufrió la actividad crediticia en el país durante el lapso estudiado en virtud de la desaceleración económica que conllevó a una disminución de la demanda de recursos orientados al financiamiento; lo cual se reflejó en un menor dinamismo de la cartera de crédito.

\subsection{Ingresos por inversiones en títulos valores/ inversiones en títulos valores promedio}

Los resultados promedio obtenidos en relación al rendimiento de las inversiones en títulos valores se presentan en la Tabla 3, se observa que, para el año 2008, el índice del estrato grande decreció mostrando cifras que oscilan entre $10,98 \%$ y $11,81 \%$, creció a inicios del 2009 a 12,79\% y decreció al final de ese año, lo cual se mantuvo a lo largo de 2010 (7,62\%). Por su parte, el estrato mediano obtuvo un índice fluctuante que logró su valor más alto para el primer trimestre de $2009(11,74 \%)$, a partir de entonces inició un descenso significativo con valores que oscilan entre $6,59 \%$ a $7,95 \%$ en el año 2010.

Por otra parte, el estrato pequeño mostró valores promedio altos desde inicios de 2008 hasta el segundo trimestre del 2009, alcanzando su máximo valor en el tercer trimestre de ese año $(17,08 \%)$; posteriormente descendió hasta el final de 2010 obteniendo cifras similares a los estratos grande y mediano. Mientras, la

\section{Gráfico 2 \\ Ingresos por Cartera de crédito/cartera de crédito promedio para el total de la banca universal}

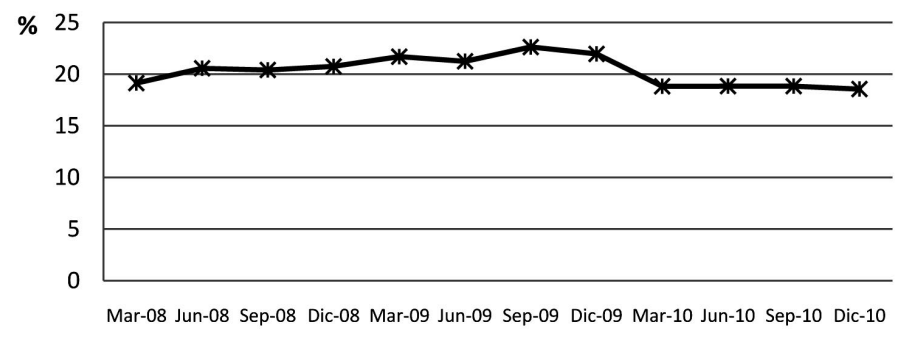

Fuente: Estimaciones propias con base en la información publicada por SUDEBAN (2008-2010). 
Tabla 3

Ingresos por inversiones en títulos valores/inversiones en títulos valores promedio*

\begin{tabular}{ccccccc}
\hline Años & $\begin{array}{c}\text { Trimestres/ } \\
\text { Estratos }\end{array}$ & Grande & Mediano & Pequeño & $\begin{array}{c}\text { Banca } \\
\text { Pública }\end{array}$ & $\begin{array}{c}\text { Banca } \\
\text { Universal }\end{array}$ \\
\hline 2 & Mar & 11,81 & 9,55 & 17,87 & 11,60 & 12,71 \\
0 & Jun & 11,21 & 9,64 & 15,20 & 12,88 & 12,23 \\
0 & Sep & 11,02 & 9,98 & 13,86 & 15,85 & 12,68 \\
8 & Dic & 10,98 & 10,27 & 14,43 & 15,71 & 12,85 \\
2 & Mar & 12,79 & 11,74 & 14,45 & 18,83 & 14,45 \\
0 & Jun & 11,36 & 10,69 & 13,71 & 17,76 & 13,38 \\
0 & Sep & 9,47 & 9,24 & 17,08 & 14,82 & 12,65 \\
9 & Dic & 9,20 & 9,11 & 12,54 & 13,50 & 11,09 \\
2 & Mar & 7,03 & 6,84 & 11,17 & 9,66 & 8,68 \\
0 & Jun & 7,15 & 6,59 & 11,11 & 7,63 & 8,12 \\
1 & Sep & 7,58 & 7,95 & 9,44 & 7,60 & 8,14 \\
0 & Dic & 7,62 & 7,68 & 9,70 & 7,51 & 8,13 \\
\hline
\end{tabular}

${ }^{*}$ Cifras relativas promedio por estrato y para el total de la Banca Universal.

Fuente: Estimaciones propias con base en la información publicada por SUDEBAN (2008-2010).

banca pública manifestó una tendencia variable con ritmo de baja; pues, en el 2008 creció hasta el segundo trimestre del 2009, desde ese momento decreció hasta el final del periodo estudiado cuando obtuvo una cifra de $7,51 \%$.

Vinculado a lo antes expuesto, en el Gráfico 3 se observa comparativamente la evolución promedio que experimentó este indicador entre los estratos; de allí, se aprecia una tendencia similar para los estratos grande y mediano, destacando el estrato pequeño por obtener cifras superiores y con ello reflejando mayor rentabilidad dentro de la banca privada en relación a sus ingresos por inversiones en títulos valores; no obstante, los tres estratos muestran una tendencia decreciente durante el período estudiado. En tanto, la banca pública reflejó un comportamiento fluctuante pero decreciente desde el segundo semestre de 2009 hasta el final de 2010, con mejores cifras que los estratos de la banca privada, lo que permite inferir mayor rentabilidad de la BU pública como producto de sus ingresos dada su inversión en títulos valores.

El Gráfico 4 permite observar la evolución promedio de este indicador en general para la BU, el cual muestra una tendencia con inclinación al alza con similitud en los valores arrojados a inicios del período estudiado oscilando entre $12,23 \%$ y $12,85 \%$, alcanzando su valor más alto en el primer trimestre de 2009 $(14,45 \%)$, cayendo a partir del segundo trimestre de ese año y mostrando una caída significativa en el año 2010 con valores muy bajos $(8,12 \%$ hasta 8,68$)$. 


\section{Gráfico 3 \\ Ingresos por inversiones en títulos valores/inversiones en títulos valores promedio entre los estratos}

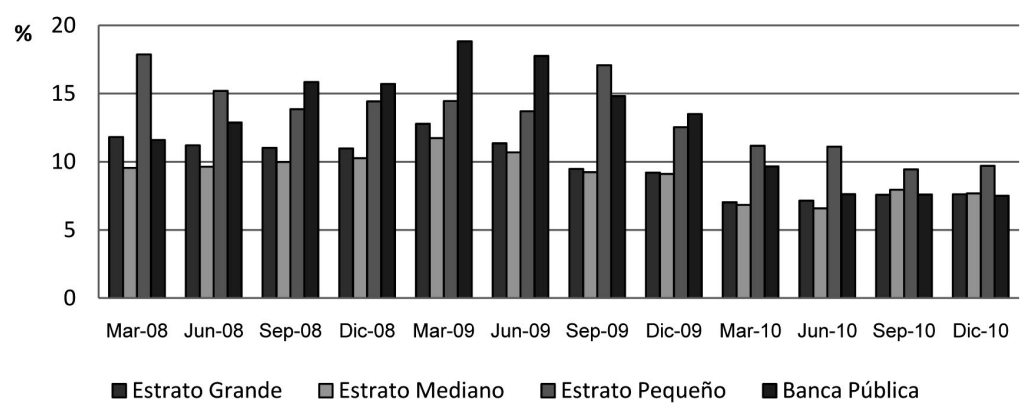

Fuente: Estimaciones propias con base en la información publicada por SUDEBAN (2008-2010).

\section{Gráfico 4 \\ Ingresos por inversiones en títulos valores/inversiones en títulos valores promedio para el total de la BU}

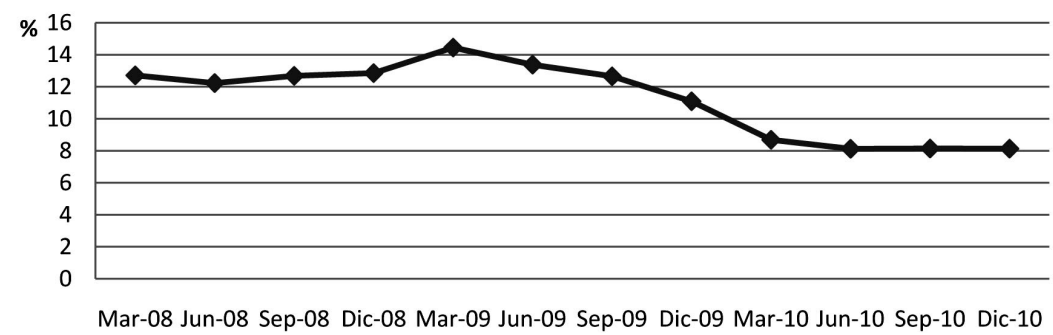

Fuente: Estimaciones propias con base en la información publicada por SUDEBAN (2008-2010).

Se considera que este comportamiento se generó por la adquisición de valores del sector público no obteniéndose los rendimientos esperados; ya que desde el año 2009 se experimentó un incremento de la participación de la banca en las emisiones de títulos públicos (vebonos, letras del tesoro y bonos) (BCV, 2009); los cuales representan un ingreso por inversiones para las entidades bancarias incrementado su cartera en títulos valores; en efecto, estas cifras sugieren que esta política de inversiones en valores logró sostener niveles de rentabilidad considerados satisfactorios y que han contribuido con la permanencia de estas instituciones en el mercado bancario nacional.

\subsection{Gastos financieros/captaciones promedio con costos}

Los resultados promedio obtenidos para el indicador Gastos Financieros/ 
Rentabilidad en la banca universal venezolana: período 2008-2010 Nava Rosillón, Marbelis Alejandra

captaciones promedio con Costos revelan valores similares entre los estratos así lo muestra la Tabla 4; donde se aprecia que el estrato grande mostró un crecimiento durante el año 2008 hasta el primer trimestre del 2009 al alcanzar su valor más alto $(13,60 \%)$, a partir de entonces comenzó un decrecimiento hasta el final del 2010 (7,86\%). Asimismo, el estrato mediano reflejó un crecimiento hasta el primer trimestre del 2009 con su máximo valor de $20,71 \%$ y una posterior disminución durante los trimestres siguientes de ese año que perduró a lo largo de todo el año 2010, en el cual reflejó el valor más bajo de $11,36 \%$, obteniendo cifras superiores al estrato grande.

Por su parte, el indicador promedio del estrato pequeño mostró un incremento durante el 2008, fluctuaciones en el 2009 proseguidas de una disminución en el 2010 que alcanzó su menor valor en el tercer trimestre de ese año $(14,43 \%)$.

Con respecto a la banca pública, esta presentó una tendencia creciente en el 2008 que osciló desde $7,13 \%$ hasta $13,39 \%$ en el primer trimestre del 2009 , mostrando fluctuaciones poco significativas en ese año y en el 2010, alcanzando su valor más alto al final del período estudiado $(14,62 \%)$.

El Gráfico 5 permite comparar la evolución de este indicador entre los estratos, de ello se observa una tendencia similar entre el estrato grande y el mediano, estos experimentaron un crecimiento desde inicios de 2008 hasta el primer trimestre de 2009 , a partir de allí comenzaron una propensión decreciente hasta finales de 2010, reflejando una situación favorable caracterizada por una disminución de los gastos financieros que se tra-

Tabla 4

Gastos financieros/captaciones promedio con Costos

\begin{tabular}{ccccccc}
\hline Años & $\begin{array}{c}\text { Trimestres/ } \\
\text { Estratos }\end{array}$ & Grande & Mediano & Pequeño & $\begin{array}{c}\text { Banca } \\
\text { Pública }\end{array}$ & $\begin{array}{c}\text { Banca } \\
\text { Universal }\end{array}$ \\
\hline 2 & Mar & 8,48 & 13,87 & 11,47 & 7,13 & 10,24 \\
0 & Jun & 9,60 & 15,81 & 12,64 & 8,61 & 11,66 \\
0 & Sep & 11,77 & 18,17 & 16,31 & 10,04 & 14,07 \\
8 & Dic & 12,12 & 18,90 & 16,13 & 10,04 & 14,30 \\
2 & Mar & 13,60 & 20,71 & 19,60 & 13,39 & 16,83 \\
0 & Jun & 12,38 & 19,25 & 18,31 & 11,68 & 15,40 \\
0 & Sep & 11,09 & 18,11 & 21,81 & 12,06 & 15,77 \\
9 & Dic & 10,80 & 16,28 & 15,27 & 11,67 & 13,51 \\
2 & Mar & 8,98 & 13,46 & 15,82 & 13,68 & 12,99 \\
0 & Jun & 8,36 & 12,34 & 15,04 & 11,64 & 11,84 \\
1 & Sep & 8,02 & 11,36 & 14,43 & 11,20 & 11,25 \\
0 & Dic & 7,86 & 12,15 & 14,90 & 14,62 & 12,38 \\
\hline
\end{tabular}

Cifras relativas promedio por estrato y para el total de la Banca Universal.

Fuente: Estimaciones propias con base en la información publicada por SUDEBAN (2008-2010). 


\section{Gráfico 5 \\ Gastos financieros/captaciones promedio con costos entre los estratos estudiados}

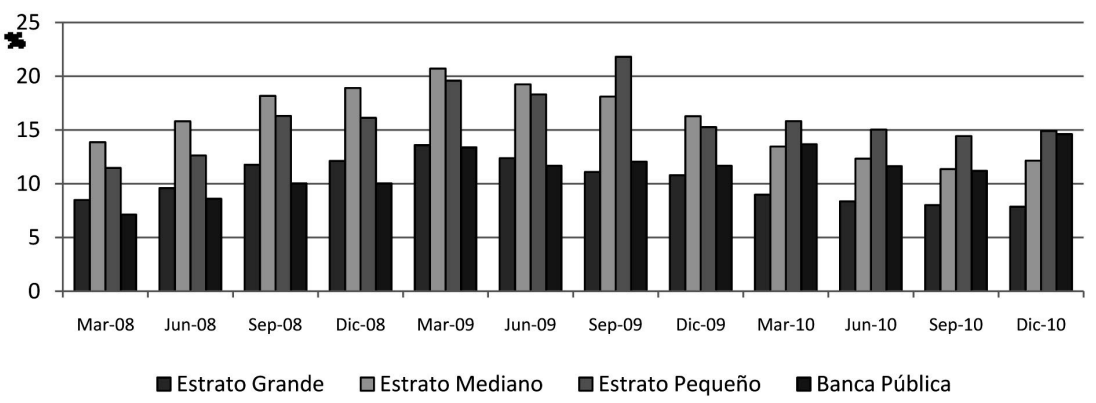

Fuente: Estimaciones propias con base en la información publicada por SUDEBAN (2008-2010).

duce en una mayor rentabilidad para estos estratos.

Mientras, el estrato pequeño mostró una tendencia fluctuante durante todo el periodo estudiado; creció al inicio y luego cayó manteniendo cifras similares entre los trimestres pero superiores a las reflejadas por el estrato grande, indicando menor rentabilidad en estas instituciones. Por su parte, la banca pública presentó una tendencia fluctuante a lo largo del tiempo de estudio con cifras menores a las alcanzadas por el resto de los estratos, sugiriendo mayor control de los gastos financieros provenientes de la cartera de captaciones siendo éstas manejadas con mayor eficiencia y reflejándose en una mayor rentabilidad para estas instituciones.

La evolución experimentada por este indicador para el total de la BU mostrada en el Gráfico 6, expresa un comportamiento fluctuante pero poco significativo durante el período estudiado; pues, las cifras arrojadas son muy próximas entre sí, oscilan entre $10,24 \%$ y $16,83 \%$, presentando una tendencia creciente al inicio y alcanzando su máximo valor en el primer trimestre de 2009, a partir de entonces se inclinó hacia la baja. Estos resultados sugieren niveles de rentabilidad satisfactorios pudiendo ser originados por la aplicación de una política de cobro que permitió recuperar las operaciones financieras, infiriendo que los pasivos a cargo de estas instituciones no resultaron tan costosos y las captaciones de recursos provenientes del público fueron suficientes para compensar los gastos financieros.

\subsection{Margen financiero bruto/activo promedio}

En lo referente a los resultados promedios arrojados por el indicador Margen Financiero Bruto/Activo promedio se observa que el estrato grande alcanzó su valor más alto de $9,30 \%$ en el primer trimestre del año 2008 experimentando un descenso que se mantuvo hasta el primer trimestre de 2010 (7,80\%), a partir de allí se incrementó hasta el final del año cuando registró un promedio de $8,56 \%$. El es- 
Rentabilidad en la banca universal venezolana: período 2008-2010 Nava Rosillón, Marbelis Alejandra

trato mediano, presentó una situación similar, reflejó su mayor valor en el primer trimestre del 2008 igual a $7,11 \%$ disminuyendo continuamente durante el resto de ese año y en el 2009; es a partir del segundo trimestre del 2010 cuando se in- crementa con cifras promedios oscilantes entre $6,30 \%$ y $6,86 \%$ (Tabla 5 ).

El estrato pequeño mostró cifras similares desde el inicio del lapso estudiado hasta finales del año 2009 cuando presentó un incremento $(9,50 \%)$, a principios

\section{Gráfico 6 \\ Gastos financieros/captaciones promedio con costos para el total de la banca universal}

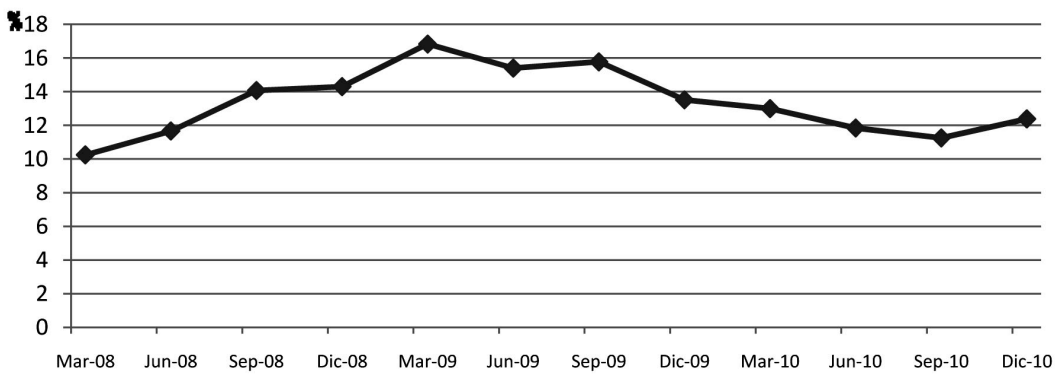

Fuente: Estimaciones propias con base en la información publicada por SUDEBAN (2008-2010).

Tabla 5

Margen financiero bruto / activo promedio*

\begin{tabular}{ccccccc}
\hline Años & $\begin{array}{c}\text { Trimestres/ } \\
\text { Estratos }\end{array}$ & Grande & Mediano & Pequeño & $\begin{array}{c}\text { Banca } \\
\text { Pública }\end{array}$ & $\begin{array}{c}\text { Banca } \\
\text { Universal }\end{array}$ \\
\hline 2 & Mar & 9,30 & 7,11 & 8,66 & 6,18 & 7,81 \\
0 & Jun & 9,22 & 6,69 & 8,31 & 6,17 & 7,60 \\
0 & Sep & 8,99 & 6,59 & 8,41 & 7,41 & 7,85 \\
8 & Dic & 8,62 & 6,52 & 8,19 & 7,20 & 7,63 \\
2 & Mar & 7,95 & 5,42 & 8,71 & 8,23 & 7,58 \\
0 & Jun & 7,86 & 5,47 & 8,55 & 7,85 & 7,43 \\
0 & Sep & 7,88 & 5,75 & 8,33 & 7,36 & 7,33 \\
9 & Dic & 7,93 & 5,56 & 9,50 & 6,59 & 7,40 \\
2 & Mar & 7,80 & 5,93 & 10,19 & 3,20 & 6,78 \\
0 & Jun & 8,12 & 6,30 & 6,91 & 3,52 & 6,21 \\
1 & Sep & 8,54 & 6,86 & 6,24 & 3,95 & 6,40 \\
0 & Dic & 8,56 & 6,57 & 6,60 & 4,25 & 6,49 \\
\hline
\end{tabular}

${ }^{*}$ Cifras relativas promedio por estrato y para el total de la Banca Universal.

Fuente: Estimaciones propias con base en la información publicada por SUDEBAN (2008-2010). 
del 2010 su promedio fue de $10,19 \%$ siendo su valor más alto durante el tiempo de estudio; no obstante, a partir del segundo trimestre experimentó una caída significativa $(6,91 \%, 6,24 \%$ y $6,60 \%)$. En tanto, la banca pública presentó resultados inferiores a los obtenidos por los estratos de la banca privada; en el año 2008 alcanzó cifras que oscilan entre $6,18 \%$ y $7,41 \%$, en el 2009 mostró una tendencia descendente que se prolongó hasta el año 2010 , en el cual alcanzó sus cifras promedios más bajas pero con tendencia al crecimiento, estas se ubican desde $3,20 \%$ hasta $4,25 \%$ (Tabla 5 ).

Ahora bien, en el Gráfico 7 se compara la evolución promedio de este indicador entre los estratos; de ello, se observa un comportamiento variable entre ellos. El estrato grande mostró una tendencia decreciente al inicio con inclinación al alza para el final del período, alcanzado cifras similares al estrato pequeño que mantuvo una tendencia poco fluctuante pero decreció a mediados del lapso; resaltó el estrato mediano con cifras inferiores sin mayor variación; la banca pública se comportó de manera muy fluctuante durante todo el pe- ríodo obteniendo valores muy por debajo de los estratos privados. Estos resultados muestran bajo margen financiero debido a la intermediación financiera denotando deficiencias en la gestión de las tasas de interés en las instituciones de BU pero especialmente en aquellas que conforman la banca pública.

En este orden de ideas, el Gráfico 8 muestra una comparación de la evolución de este indicador para el total de la BU, donde se observa un comportamiento similar a lo largo del período de estudio sin mayores fluctuaciones y con tendencia descendente en el año 2010, con valores que se ubican por debajo del $8 \%$. Estas cifras sugieren baja ganancia neta obtenida por la intermediación ejercida por las instituciones de BU reflejando ineficiencia en la gestión de las tasas de interés pasiva y activa, en lo cual se considera que incidió el establecimiento de topes máximos a las tasas de interés de algunos sectores económicos en el 2008, a los ajustes realizados a estas tasas que provocaron una disminución generalizada tanto de las tasas activas como de las pasivas en el año 2010.

\section{Gráfico 7 \\ Margen financiero bruto/activo promedio entre los estratos estudiados}

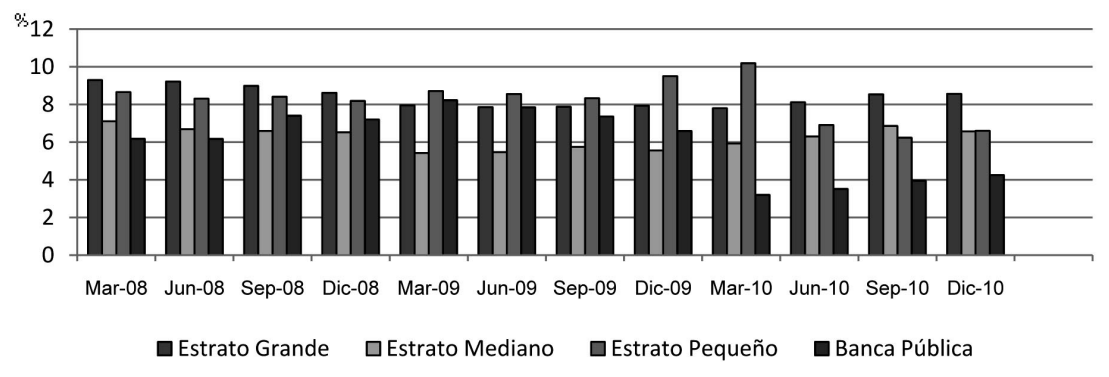

Fuente: Estimaciones propias con base en la información publicada por SUDEBAN (2008-2010). 


\section{Gráfico 8 \\ Margen financiero bruto/activo promedio para el total de la banca universal}

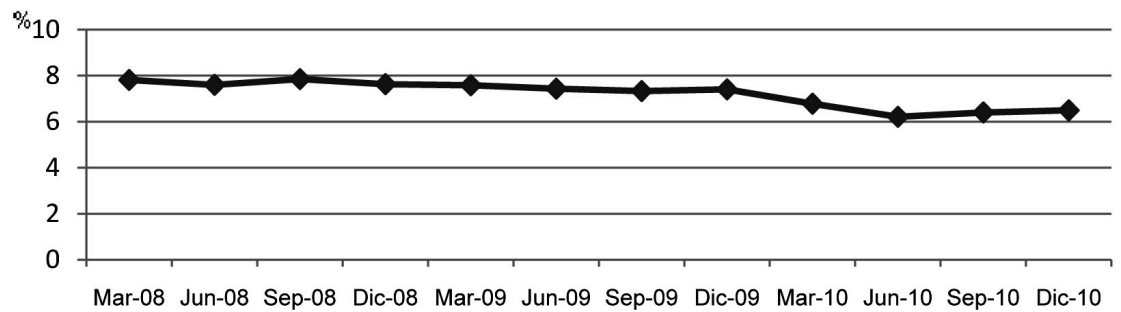

Fuente: Estimaciones propias con base en la información publicada por SUDEBAN (2008-2010).

\subsection{Resultado neto / activo promedio (ROA)}

Para el indicador Resultado Neto/Activo Promedio (ROA), se obtuvieron cifras promedios muy similares entre los estratos estudiados; siendo el estrato grande el que alcanzó cifras más altas entre ellos. Este estrato mostró promedios para el año 2008 que oscilan entre $3,47 \%$ y $3,88 \%$, los cuales decrecieron para el año 2009 y 2010 presentando fluctuaciones poco significativas. Por su parte, el estrato mediano obtuvo promedios desde $2,66 \%$ a $2,76 \%$ en el año 2008 , cayó desde el primer trimestre del 2009 con una cifra de $1,99 \%$ manteniendo valores similares hasta el cuarto trimestre del 2010 en el cual se recuperó y logró una cifra de 2,14\% (Tabla 6).

$\mathrm{Al}$ respecto, el estrato pequeño obtuvo su valor más alto en el primer trimestre del $2008(4,52 \%)$ pero presentó una tendencia decreciente durante ese año; contrario a ello, en el 2009 tuvo un crecimiento de $1,01 \%$ a $3,11 \%$ y para el año
2010 decreció alcanzando sus cifras más bajas durante el período de estudio. La banca pública mostró los resultados más bajos entre los estratos, presentó fluctuaciones poco significativas con cifras que oscilan entre $0,55 \%$ y $1,97 \%$ durante el lapso de estudio (Tabla 6).

Al comparar entre los estratos la evolución de este indicador a lo largo de los tres años estudiados (Gráfico 9), se observa que los estratos grande y mediano se comportaron de manera similar con diferencias en sus cifras. El estrato pequeño mostró una significativa variabilidad con cifras muy bajas al igual que la banca pública, sugiriendo estos resultados bajo rendimiento de las inversiones realizadas por estas instituciones bancarias como consecuencia de la poca efectividad en la gestión de sus colocaciones.

Por otra parte, comparando la evolución del ROA para el total de la BU (Gráfico 10), se denota un comportamiento bastante fluctuante con inclinación decreciente a lo largo del periodo estudiado, reflejando cifras desde $3,16 \%$ en el primer 
Tabla 6

Resultado neto / activo promedio (ROA)

\begin{tabular}{ccccccc}
\hline Años & $\begin{array}{c}\text { Trimestres/ } \\
\text { Estratos }\end{array}$ & Grande & Mediano & Pequeño & $\begin{array}{c}\text { Banca } \\
\text { Pública }\end{array}$ & $\begin{array}{c}\text { Banca } \\
\text { Universal }\end{array}$ \\
\hline 2 & Mar & 3,88 & 2,74 & 4,52 & 1,52 & 3,16 \\
0 & Jun & 3,59 & 2,66 & 3,31 & 1,03 & 2,64 \\
0 & Sep & 3,47 & 2,74 & 1,95 & 0,96 & 2,28 \\
8 & Dic & 3,63 & 2,76 & 0,95 & 1,00 & 2,90 \\
2 & Mar & 2,65 & 1,99 & 1,01 & 1,10 & 1,69 \\
0 & Jun & 2,94 & 1,83 & 2,11 & 1,30 & 2,04 \\
0 & Sep & 2,75 & 1,84 & 2,92 & 1,88 & 2,35 \\
9 & Dic & 2,73 & 1,97 & 3,11 & 1,97 & 2,44 \\
2 & Mar & 2,67 & 1,60 & 1,32 & 0,55 & 1,54 \\
0 & Jun & 2,77 & 1,86 & 0,56 & 0,83 & 1,51 \\
1 & Sep & 2,82 & 1,98 & 0,47 & 1,04 & 1,58 \\
0 & Dic & 2,91 & 2,14 & 0,74 & 1,04 & 1,70 \\
\hline
\end{tabular}

Cifras relativas promedio por estrato y para el total de la Banca Universal.

Fuente: Estimaciones propias con base en la información publicada por SUDEBAN (2008-2010).

\section{Gráfico 9 \\ Evolución del ROA entre los estratos estudiados}

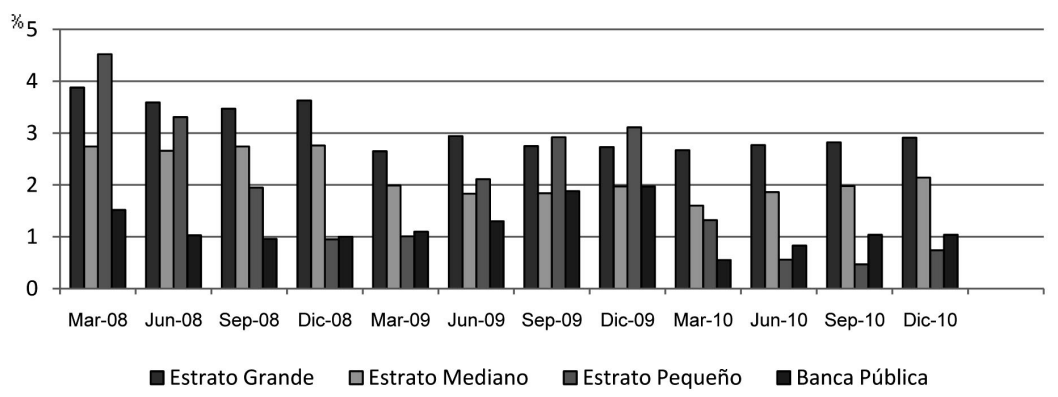

Fuente: Estimaciones propias con base en la información publicada por SUDEBAN (2008-2010).

trimestre de 2008 hasta $1,70 \%$ al final de 2010. Resultados que indican baja efectividad en la utilización o gestión de sus inversiones en activos de las entidades bancarias con modalidad de BU, reflejándose en bajas ganancias netas con res- pecto al valor de los activos pertenecientes a estas instituciones. Esta situación se traduce en una disminución en el rendimiento de la gestión financiera de la BU en relación con la cantidad de bolívares invertidos en activos. 


\section{Gráfico 10 \\ Evolución del ROA para el total de la banca universal}

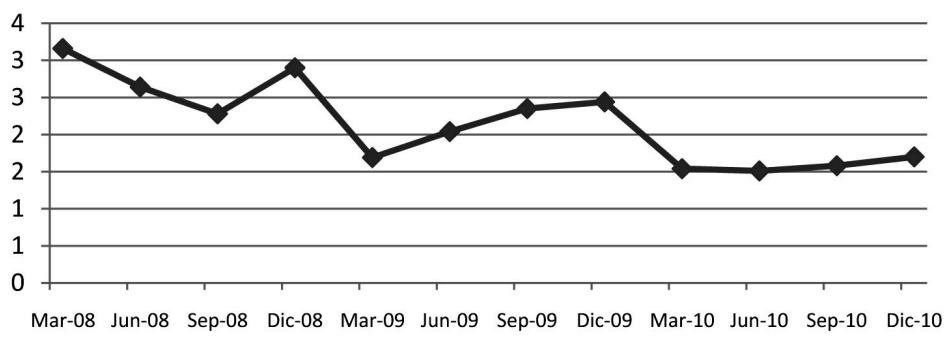

Fuente: Estimaciones propias con base en la información publicada por SUDEBAN (2008-2010).

\subsection{Resultado neto / patrimonio promedio (ROE)}

Con respecto al indicador resultado neto/patrimonio promedio, se obtuvieron resultados que difieren entre los estratos estudiados; pues, el estrato grande con mayores captaciones del público mostró una tendencia decreciente durante los tres años; a principios de 2008 obtuvo su promedio más alto de $43,05 \%$ disminuyendo en el tercer trimestre a $37,92 \%$ y se recuperó en el cuarto trimestre con un promedio de 40,78\%; pero disminuyó en el año 2009 durante el cual mostró fluctuaciones pocos significativas con cifras desde $28,38 \%$ hasta $32,39 \%$ y en el 2010 presentó una tendencia creciente desde $27,26 \%$ a $30,16 \%$ (Tabla 7 ).

El estrato mediano registró promedios similares durante el 2008, una tendencia fluctuante durante el 2009 y cayó significativamente a inicios del 2010 $(17,74 \%)$ recuperándose al final del año con una cifra de $24,77 \%$. Mientras que el estrato pequeño muestra resultados promedio inferiores a los estratos grande y mediano, inició el año 2008 con valores de $18,93 \%$ y creció hasta $21,50 \%$ en el segundo trimestre pero cayó significativamente a $6,44 \%$ en el primer trimestre de 2009 y experimentó un alza que alcanzó $21,93 \%$ al final del año; contrario a ello en el 2010 mostró una disminución relevante con cifras muy bajas oscilantes entre $3,24 \%$ y $7,52 \%$ (Tabla 7 ).

Por su parte, el índice promedio de la banca pública presentó cifras próximas al estrato pequeño, con tendencia muy fluctuante durante el lapso estudiado, alcanzó su valor más alto en el último trimestre de $2009(22,06 \%)$ y su valor más bajo en el primer trimestre de 2010 (7,10\%), así lo revela la Tabla 7 .

No obstante, el Gráfico 11 muestra un comportamiento disímil del indicador ROE entre los estratos; de allí, se percibe una tendencia variante con inclinación hacia la baja por parte del estrato grande pero alcanzando los mayores valores con respecto al resto de los estratos; el estrato mediano fluctuó en forma descendente durante el período de estudio mostrando bajo rendimiento del capital propio; el es- 
Tabla 7

Resultado neto / patrimonio promedio (ROE)*

\begin{tabular}{ccccccc}
\hline Años & $\begin{array}{c}\text { Trimestres/ } \\
\text { Estratos }\end{array}$ & Grande & Mediano & Pequeño & $\begin{array}{c}\text { Banca } \\
\text { Pública }\end{array}$ & $\begin{array}{c}\text { Banca } \\
\text { Universal }\end{array}$ \\
\hline 2 & Mar & 43,05 & 32,77 & 18,93 & 15,68 & 27,61 \\
0 & Jun & 40,17 & 32,40 & 21,50 & 9,96 & 26,01 \\
0 & Sep & 37,92 & 32,16 & 13,54 & 8,77 & 23,10 \\
8 & Dic & 40,78 & 32,07 & 13,05 & 9,95 & 23,96 \\
2 & Mar & 28,38 & 26,47 & 6,44 & 11,33 & 18,16 \\
0 & Jun & 32,39 & 23,93 & 12,47 & 14,21 & 20,75 \\
0 & Sep & 30,05 & 23,00 & 20,67 & 20,98 & 23,67 \\
9 & Dic & 29,88 & 26,07 & 21,93 & 22,06 & 24,98 \\
2 & Mar & 27,26 & 17,74 & 7,52 & 7,10 & 14,91 \\
0 & Jun & 28,87 & 21,04 & 4,00 & 11,25 & 16,29 \\
1 & Sep & 28,74 & 21,35 & 3,24 & 14,70 & 17,01 \\
0 & Dic & 30,16 & 24,77 & 5,58 & 14,42 & 18,73 \\
\hline
\end{tabular}

*Cifras relativas promedio por estrato y para el total de la Banca Universal.

Fuente: Estimaciones propias con base en la información publicada por SUDEBAN (2008-2010).

\section{Gráfico 11 \\ Evolución comparativa del ROE entre los estratos estudiados}

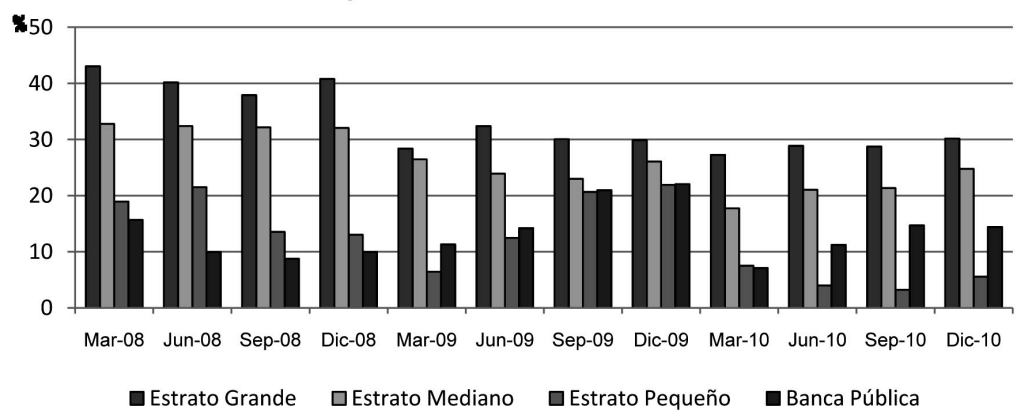

Fuente: Estimaciones propias con base en la información publicada por SUDEBAN (2008-2010).

trato pequeño y la banca pública alcanzaron cifras inferiores al $22 \%$ con una tendencia variante en forma significativa, sugiriendo que el capital de los accionistas no generó rendimientos satisfactorios a las instituciones.
Estos resultados son considerados coeficientes bajos en función del parámetro establecido para este indicador; ya que alcanzar valores por debajo de $30 \%$ es indicativo de bajo rendimiento de los recursos aportados por los socios; sólo el 
Rentabilidad en la banca universal venezolana: período 2008-2010 Nava Rosillón, Marbelis Alejandra

estrato grande alcanzó valores mayores al $30 \%$ en los dos primeros años del lapso de estudio, lo cual evidencia que este estrato obtuvo mayor rentabilidad sobre el patrimonio con respecto al resto de los estratos.

Por su parte, el Gráfico 12 compara la evolución del ROE promedio para el total de la BU, evidenciando una tendencia muy fluctuante con inclinación decreciente entre los trimestres de los años 2008 y 2010, sólo presentó ritmo creciente en el 2009; en general, mostró cifras que se ubican por debajo del $30 \%$ con una caída significativa en el primer trimestre del 2010 (14,91\%); lo cual indica que los fondos o recursos invertidos por los accionistas de las instituciones con modalidad de $\mathrm{BU}$ no generaron rendimientos positivos a estos inversionistas sugiriendo una pérdida económica significativa para la BU que conlleva a hacer uso del capital propio o invertido por sus accionistas para cubrir sus costos y compromisos; esto indica la utilización de capital adicional para financiar algunas operaciones.

\section{Conclusiones}

La tendencia reflejada por los indicadores promedios para el período 2008-2010, evidenció que la BU en Venezuela ha sido capaz de alcanzar y mantener niveles de rentabilidad satisfactorios sin diferencias significativas entre los estratos, los cuales la caracterizan como una modalidad de banca viable y sólida en el mercado bancario venezolano; mostrando para los diferentes estratos, un comportamiento en función de las utilidades obtenidas cuya tendencia es creciente al inicio del lapso de estudio con inclinación hacia la baja para el último año.

Se considera que estas instituciones disponen una cartera de crédito beneficiosa, a pesar del decrecimiento de la actividad crediticia en el país como consecuencia de la desaceleración de la economía que originó la disminución del financiamiento, al alcanzar índices promedios similares entre los estratos de la banca privada los cuales resultaron superiores a los promedios de la banca pública,

\section{Gráfico 12}

\section{Evolución del ROE para el total de la Banca Universal}

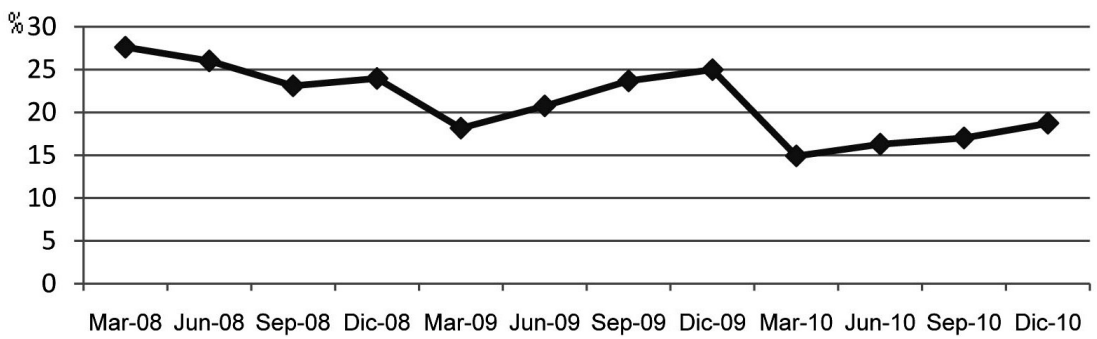

Fuente: Estimaciones propias con base en la información publicada por SUDEBAN (2008-2010). 
con ello se manifiesta menor rentabilidad por parte de esta última.

El rendimiento de las inversiones en títulos valores evidenció una tendencia variable con ritmo hacia la baja, lo cual refleja resultados contrarios a los esperados por estas instituciones al incrementar su inversión en títulos públicos; de ello, se destaca una similitud entre los índices promedios obtenidos por el estrato grande y el estrato mediano.

También, se encontró una tendencia creciente al inicio del período estudiado pero decreciente para el año 2010 al relacionar los gastos financieros con las captaciones promedio con costos; sugiriendo que la BU dispone pasivos con costos bajos y suficientes recursos captados para compensar sus gastos financieros. Al respecto, el estrato pequeño obtuvo las cifras más altas expresando mayor rentabilidad en la banca privada mientras que la banca pública obtuvo los mejores índices denotando mayor rentabilidad dentro de la BU.

Se obtuvieron bajos índices promedios que reflejaron baja ganancia neta generada por la intermediación financiera de la BU, lo que refleja deficiencias en la gestión de las tasas de interés especialmente por las instituciones de la banca pública. Ahora bien, los estratos grande y mediano reflejaron mayor rentabilidad dentro de la banca privada, ya que el estrato pequeño denotó cifras superiores a estos.

Por otra parte, se considera la gestión de los activos de estas entidades bancarias poco efectiva, debido a que el índice ROA mostró un comportamiento fluctuante con tendencia decreciente a lo largo del lapso estudiado, donde el estrato grande obtuvo la mayor rentabilidad con respecto al resto de los estratos refle- jando ganancias netas altas dada su inversión en activos, mientras la banca pública obtuvo el ROA más bajo.

Igualmente, el índice ROE para la $\mathrm{BU}$ presentó valores muy bajos con fluctuaciones a un ritmo decreciente siendo notorio que estas instituciones no generaron rendimientos positivos a sus accionistas. Entre los estratos, se evidencian diferencias significativas, la mayor rentabilidad fue obtenida por el estrato grande; en tanto, el estrato pequeño y la banca pública alcanzaron cifras inferiores que denotan baja rentabilidad.

Con base en las consideraciones anteriores, se deduce que las instituciones con modalidad de BU con capital privado muestran mayor rentabilidad y eficiencia mientras que las entidades con capital público mejoraron sus resultados a lo largo del período de estudio, reflejando un acercamiento entre los diferentes estratos.

Finalmente, la rentabilidad está totalmente relacionada con la capacidad de la banca para obtener ganancias de sus operaciones reflejadas en la eficiencia de su desempeño gerencial; pues, el tamaño de las entidades bancarias expresado en función del monto de sus captaciones del público no determina altos niveles de rentabilidad sino que en estos incide la eficiencia y efectividad en la gestión de sus operaciones y los factores del entorno tanto interno como externo.

Sin embargo, las instituciones bancarias venezolanas con modalidad de BU están realizando un gran esfuerzo para lograr una verdadera adaptación a las nuevas tendencias globalizadoras de la economía mundial; por ello, deben seguir su proceso de crecimiento en el futuro para incrementar sus niveles de eficien- 
cia y rentabilidad dentro del mercado bancario venezolano.

Del mismo modo, se considera necesario que la comunidad financiera en Venezuela debe tomar acciones que permitan evitar nuevas crisis bancarias siguiendo los fundamentos del nuevo proceso de globalización y que evidencien eficiencia, efectividad y transparencia en la gestión operativa de las instituciones financieras.

\section{Referencias bibliográficas}

Asamblea Nacional de la República Bolivariana de Venezuela (2010). Ley de Instituciones del Sector Bancario. Gaceta Oficial $N^{\circ} 6.015$. Diciembre. Venezuela. Disponible en: www.asambleanacional.gov.ve. Fecha de Consulta: 28/04/2011.

Banco Central de Venezuela, BCV (2008). Informe Económico. Caracas. Venezuela.

Banco Central de Venezuela, BCV (2009). Informe Económico. ( $1^{\text {ra }}$ ed.) Caracas. Venezuela.

Banco Central de Venezuela, BCV (2010). Informe Económico. ( $1^{\text {ra }}$ ed.) Caracas. Venezuela.

Belloso, Nora; Primera, Nelly (2005). Sistema de Información en la Banca Universal Venezolana. Revista de Ciencias Sociales. Volumen. XI. No. 1. Maracaibo. Venezuela. Facultad de Ciencias Económicas y Sociales. La Universidad del Zulia. Pp 118-130.

Block, Stanley; Hirt, Geoffrey (2001). Fundamentos de Gerencia Financiera. Novena edición. Bogotá, Colombia. Mc Graw Hill.

Brigham, Eugene; Houston, Joel (2006). Fundamentos de Administración Financiera. (10 $\mathrm{Ed}$.). México. Learning Editores.
Congreso Nacional de la República de Venezuela (1993). Ley General de Ban$\cos$ y otras Instituciones Financieras. Gaceta Oficial N ${ }^{\circ} 4.649$. Noviembre. Venezuela.

Díaz Mondragón. Manuel (2004). "Los Bancos Globales y sus Implicaciones en México". Economía Informa. № 325. Abril. México. Pp 91-100.

Fondo Monetario Internacional (2006). Indicadores de Solidez Financiera. Guía de Compilación. Washington D.C. Disponible en: http://www.imf.org.

Gitman, Lawrence (2003). Principios de Administración Financiera $\left(10^{\mathrm{a}} \mathrm{Ed}\right.$.) México. Prentice Hall.

Hernández Sampieri, Roberto; Fernández, Carlos; Baptista, Pilar (2003). Metodología de la Investigación ( $3^{\text {era }}$ ed.). México. Mc Graw Hill.

Hurtado, Jacqueline (2007). El Proyecto de Investigación. Metodología de la investigación Holística ( $5^{\mathrm{a}}$ ed.). Caracas, Venezuela. Quirón.

Linares, Humberto (2001). Banca Venezolana, Historia, Administración de Crédito y Operaciones. (2 $2^{\text {da }} E d$.). Fondo Editorial Universidad Santa María. Venezuela.

Méndez, Carlos (2001). Metodología. Diseño y Desarrollo del Proceso de Investigación. $3^{a}$ Edición. Colombia. Mc Graw Hill.

Muci Facchin, Gustavo; Martín Ponte, Rafael (2004). Regulación Bancaria. Universidad Católica Andrés Bello. Fundación Banco Mercantil (1 ${ }^{a}$ Ed.). Caracas, Venezuela. Pp 370.

Nava Rosillón, Marbelis (2009). Análisis Financiero: Una herramienta clave para una Gestión Financiera eficiente. Revista Venezolana de Gerencia. Año 14. № 48. Maracaibo, Venezuela. Centro de Estudios de la Empresa. Universidad del Zulia. Pp 606-628. 
Nava Rosillón, Marbelis (2011). Incidencia de la Banca Universal en el Sistema Financiero Venezolano. Revista Venezolana de Gerencia. Año 16. № 55. Maracaibo, Venezuela. Centro de Estudios de la Empresa. Universidad del Zulia. Pp 474-491.

Rodriguez, Abigail; Venegas, Francisco (2010). Indicadores de Rentabilidad y Eficiencia Operativa en la Banca Comercial en México. Problemas del Desarrollo. Revista Latinoamericana de Economía. Volumen 41. $\mathrm{N}^{\circ}$ 161. México. Universidad Nacional Autónoma de México. Pp 165-191.

Superintendencia de Bancos y otras Instituciones Financieras, SUDEBAN (2008).
Boletín Trimestral. Indicadores Financieros. Año 15. Caracas. Venezuela.

Superintendencia de Bancos y otras Instituciones Financieras, SUDEBAN (2009). Boletín Trimestral. Indicadores Financieros. Año 16. Caracas. Venezuela.

Superintendencia de Bancos y otras Instituciones Financieras, SUDEBAN (2010). Boletín Trimestral. Indicadores Financieros. Año 17. Caracas. Venezuela.

Van Horne, James; Wachowicz, Jhon (2002). Fundamentos de Administración Financiera $\left(11^{a}\right.$ ed.). México. Prentice Hall. Pp 768. 